\title{
The Ordinary College Undergraduate Course Teaching Mode Research $^{*}$
}

\author{
Jianling Wang ${ }^{1}$, Hongbo Lai ${ }^{2}$ \\ ${ }^{1}$ College of Engineering Science\&Technology, Shanghai Ocean University, shanghai, China \\ ${ }^{2}$ School of Art Design and Media, East China University of science and technology, Shanghai, China \\ Email: jlwang20042005@163.com
}

Received 2012

\begin{abstract}
The teaching mode is reformed for the university talents training target, namely the cultivation of innovative talents. The teaching model is introduced into the classroom, compared with the traditional teaching model, the teaching mode gains achieved good results.
\end{abstract}

Keywords: Classroom Teaching; Innovative Thinking; Method Reform

\section{Introduction}

Teaching mode can be defined as: under the guidance of the certain teaching ideas and teaching theory, around the certain teaching goals, to finish the teaching task and set up relatively stable teaching activities of "paradigm"[1]. The students of ordinary higher school which basis is weaker than the students of research higher schools, so the ordinary higher schools in China carry out "teaching is primary, scientific research is subordinate" as the goal.The undergraduate talents training goal mainly locates in the training of the students' practice ability and innovation ability, the course settings and practice settings are corresponding adjusted, but also on the teachers' classroom teaching is puted forward new demands.

\section{Student Groups Hierarchy}

In traditional teaching, classroom teaching progress often bases on the students which levels are moderate and difficultly consider the students which levels are good or poor. Nearly $20 \%$ of good students, classroom teaching can not meet their learning needs; and almost $20 \%$ of poor students can not understand, unable to complete their studies.

For the three class students need teachers to different treatment: secondary students in accordance with the requirements of its normal teaching schedule master knowledge within the classroom; students with good foundation, encourage them to take part in various types of project declaration, such as innovation project, to enable students to master the project reporting, planning, construction in terms of the specialized knowledge and skills, and by doing all kinds of projects, so that its knowledge to learn in order to practice; students with poor foundation, encourage and guide them to take part in the various kinds of test of the occupation qualification certificate, to lay a good foundation for their future employment.

\section{Based on the Content}

For the basic teaching content here divides it into the digital

*Foundation item: 2012 University Key Course Construction (Operations Research \& Systems Engineering, A-2600-12-0000-10). calculation content and concept category content. For calculation digital content, in the theoretical deduction of the formula, due to operational symbol is abstract, not mathematics major students understand difficultly, so it is necessary to specific digital auxiliary derivation; for example explains, if only to show the slides courseware, some students can not catch knowledge much, some students can not understand, some students are feeling all understand, but their titles can do nothing.In view of this situation, teachers can make an example decomposed into several steps, let students base on the corresponding theoretical formula by each step of the operation, with every step, teacher write out the correct answer and explanation of the step at blackboard, and then students check their answers, which can timely understand the cause of the error in every step, and is corrected in time, such an example completed, students is very clear the solving process for this class of problem.

\section{Case Teaching}

Case teaching method is that teachers according to the teaching content and the teaching goal, through the creation of a case, case as the basic materials, organize the students to carry out research, analysis, expression and other activities, lets the student in the specific situation of positive thinking, active exploration, to cultivate the students' comprehensive quality of a teaching method[2]. On the textbook knowledge summary is the universal law, case teaching can make students with basic theories to explain the phenomenon, thereby shortening the distance between teaching context and teaching theory. Also due to the teaching and scientific research projects are closely linked, in case of, and research project to link in scientific research project, we will encounter some new problems, to these new problems and solve methods into classroom, can not only make up for the lack of textbooks, but also can arouse students' interest in learning, make students change from knowledge, memories into thinking training.

\section{Practice Teaching}

Practice teaching is an important part of undergraduate teaching, which has application and supplementary role for the 
theory teaching contents, enables students to apply theoretical knowledge to practice, but also improves their thinking ability innovation ability and the ability to solve practical problems. In order to cultivate the innovative talents, school encourages to make the practice teaching into the curriculum.

Practice content not only conform to the teaching content, but also closely connect with the society and the needs of industry, with the development of the society, which need to be constantly updated, so as to make students always pay attention to professional development and absorb new knowledge, according to science and technology development, which can increase the breadth and depth of their knowledge structure. In the past practice, the traditional teaching method is a topic, let all students do this one problem, so that the content limitations which the students can do is too small, sometimes a problem is not transformed in a few years, the contents is old. Along with the social needs constantly updated, practical teaching content and practical teaching methods need to be improved. In practice we can let each student a topic and also let the students self subject. Through the teachers and students interacting, complete the course teaching practice.

After determining the subject, teachers can help each group of students to solve the core problem and the difficulty. In this process, the emphasis should let students into a learning state, according to their level of knowledge and practice requirement, choose their own way, gradually get rid of teacher s ' help, achieve self control and self regulation in the practice process.

Practice teaching should not only attach importance to teaching process, but also pay attention to the teaching effect. For learning in order to practice, curriculum design and various competitions can be linked, such as innovation competition, let students use the curriculum design to declare competition, after expert assessment the students can know their own level and have the foundation for graduation thesis.

To sum up, the practice teaching process is as follows:

The first step: student grouping, identify each theme in practice;

The second step: determine the core content of practice;

The third step: effective teaching practice;

The fourth step: practice application: declare competition.

\section{Teaching Effect}

Teaching mode will directly affect the efficiency and effect of the teaching process, compared with the past teaching mode " explain-accept", the problem, heuristic, exploration, interactive of teaching mode can arouse the students' learning enthusiasm and initiative, which is conducive to the cultivation of students' innovative ability.

In order to evaluate the teachers' teaching, each university has a teaching evaluation system for teachers, teaching quality and effect are evaluated, in order to promote the improvement of the teaching process and to improve teaching quality. Taking Shanghai Ocean University as an example, its teaching evaluation index and weight are as follows Table 1.

In this paper, for the ordinary college undergraduate course the teaching mode is constantly explored in the process of teaching, summed up a few years continuously, and applied in the practical teaching, and achieved good results. The " operations research and systems engineering" course is used as an example, the teaching object is the industrial engineering students of Shanghai Ocean University, the grade 2006 students
Table 1.

Shanghai Ocean University teaching evaluation.

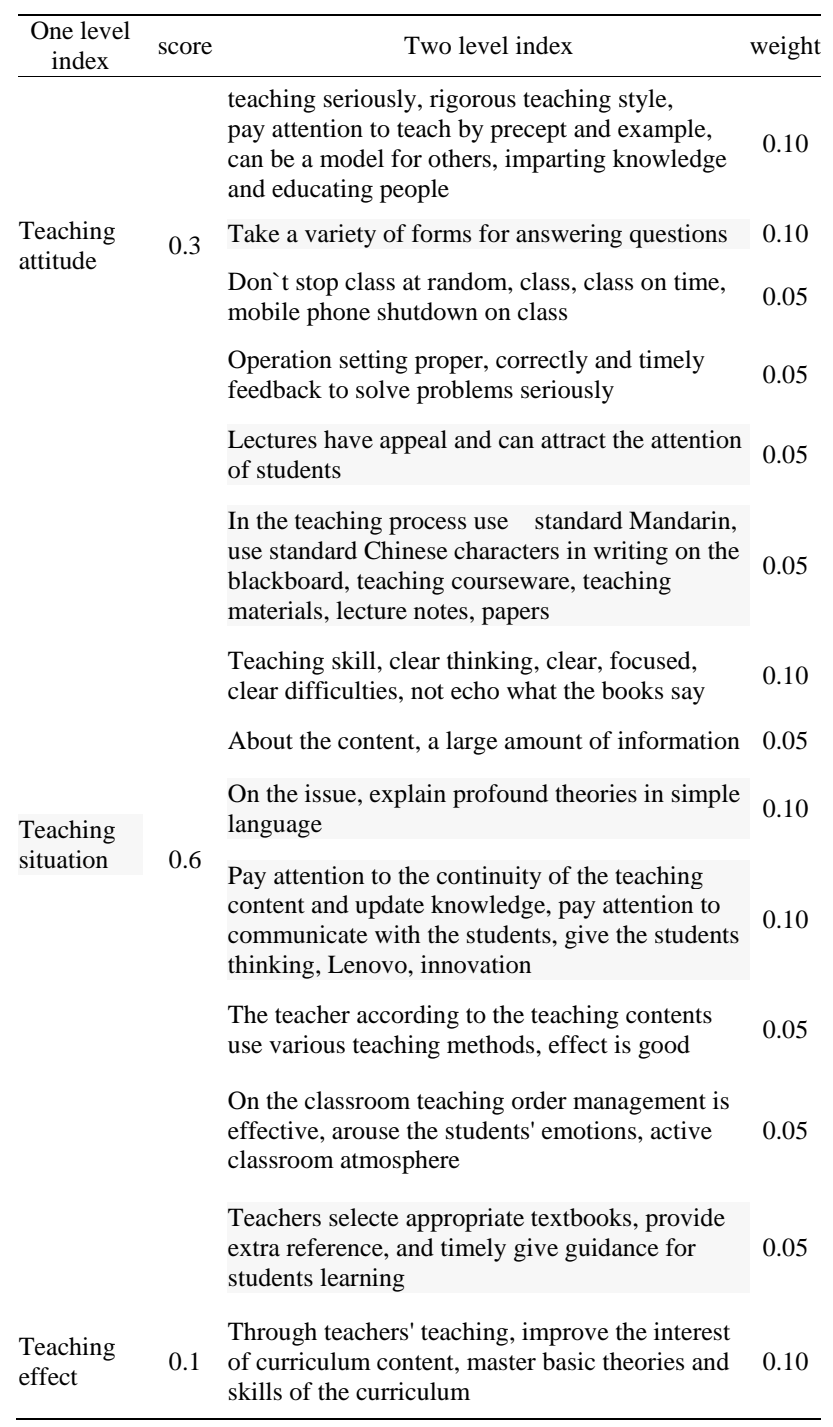

Table 2.

"Operations research and systems engineering" teaching evaluation.

\begin{tabular}{|c|c|c|}
\hline \multicolumn{3}{|c|}{$\begin{array}{l}\text { Term: the second semester of 2007-2008 schoc } \\
\text { Speciality: } 2006 \text { Industrial Engineering } \\
\text { The effective questionnaire number: } 45\end{array}$} \\
\hline Teaching attitude & Teaching situation & Teaching effect \\
\hline 28.88 & 43.03 & 7.89 \\
\hline \multicolumn{3}{|l|}{ Total score: 79.80} \\
\hline \multicolumn{3}{|c|}{$\begin{array}{l}\text { Term: the second semester of 2010-2011 school year } \\
\text { Speciality: } 2009 \text { Industrial Engineering } \\
\text { The effective questionnaire number: } 52\end{array}$} \\
\hline Teaching attitude & Teaching situation & Teaching effect \\
\hline 27.64 & 54.97 & 8.79 \\
\hline
\end{tabular}

are used the traditional teaching method, the grade 2009 students are used the new teaching method. The teachers' teaching evaluation for the two grades`students are as follows Table 2. 
From Table 1 and Table 2, we can see that the current teaching method is better than the traditional teaching method, the student evaluation score is high.

\section{REFERENCES}

Liu Chengkun. Teaching Mode Exploration on Advancing Undergraduate Freedom Study. China Higher Education,2011,17:58-59
Kuai Xiuli. Case Teaching Method in Education Teaching Application. Education Exploration, 2011,12(246):50-51

L.Dee Fink; LI Kang. A Self-Directed Guide to Designing Courses for Significant Learning: Designing Courses That Promote Significant Learning. Fudan Education Forum,2008,1(6):72-80

Yu Li; Fu Yan; Li Shiqi. Exploring the Opening Model of Training Talents in Industrial Engineering Specialty. Research in Higher Education of Engineering,2011,6:141-145 